\title{
Modelling Investigation of the Heat Transfer in a Polycrystalline Photovoltaic Module
}

\author{
Ibtissam Lamaamar, ${ }^{1, *}$, Amine Tilioua ${ }^{1}$, Zaineb Benzaid ${ }^{1}$ and Moulay Ahmed Hamdi Alaoui ${ }^{2}$ \\ ${ }^{1}$ Research Team in Thermal and Applied Thermodynamics (2.T.A.), Mechanics, Energy Efficiency and Renewable Energies Laboratory \\ (L.M.3.E.R.), Department of Physics, Faculty of Sciences and Techniques Errachidia, Moulay Ismaïl University of Meknès, B.P. 509, \\ Boutalamine, Errachidia, Morocco. \\ ${ }^{2}$ MM, Faculty of Sciences, University Moulay Ismaïl, Department of Physics, B.P. 11201 Zitoune 5000 Meknes, Morocco
}

\begin{abstract}
The heat transfer inside a photovoltaic (PV) module is affected by the thermo-physical properties of the module layers, the weather conditions and the surrounding environment. In this work, the heat transfer inside a PV module is described in detail, taking into account realistic boundary conditions at the module surface. We have developed a one-dimensional (1D) thermal model using the finite volume (FV) method. The results of the developed model were validated with the results of the literature. We then tested the reliability of the developed model by comparison with experimental data from the climatic conditions of the region of Errachidia Drâa-Tafilalet, and the data obtained by other empirical and analytical models of the literature. We found that the results of the developed model are in good agreement with the experimental data, and calculates better the temperature of cells.
\end{abstract}

\section{Introduction}

The conversion of sunlight into electrical energy by PV cells remains the most interesting technique in the world of renewable energy. Only 5 to $25 \%$ of electricity is produced by typical PV panel after conversion of incident light, and the rest is transformed into heat which increases the operating temperature of the PV panel [16]. Several studies have described the thermal behaviour of the PV module, some authors ignore certain heat transfer mechanisms by simplifying the thermal network $[7,8]$. We find different correlations that have been developed to estimate the temperature of solar cells. These correlations are based on the weather conditions and the electrical and optical characteristics of the PV module [9-12].

An analytical thermal model to preview the temperature of PV cells with varying environmental conditions is made by Jones and Underwood [13]. Based on the hypotheses of their model, which concerned that the entire panel is at uniform temperature, a difference of $6^{\circ} \mathrm{C}$ is found between the predicted and measured temperature. In contrast, to estimate the electrical performance of a hybrid thermal photovoltaic (PV/T) system, Sarhaddi et al. [14] developed a 1-D thermal model. They considered both convective and radiative heat losses from the front surface; on the other hand, they totally ignored the radiative losses from the back layer. Lee et al [15] to examine the thermal behavior of the PV module, by predicting the temperature distribution of each layer, they used the finite element method. They found that the cells closer to the frame have a temperature difference of $5^{\circ} \mathrm{C}$ compared to the cells in the center of the module. Armstrong developed the thermal model, which describes the material composition of the PV panel, by modeling the thermal response of the PV panel as an RC circuit. Then they analyzed the effect of convective and radiative losses on the thermal behavior of the PV panel [16]. Three layers, glass, solar cells and the back layer, were considered in the thermal model developed by Tina et al. [17], because of the high thermal storage potential of a photovoltaic panel, steady state or quasi-steady-state models are not valid for precise temperature prediction. King et al [18] developed a model expressed by an empirical equation that computes the cell temperature as a function of the measured back side temperature of the module, the incident radiation, the wind speed and a temperature constant depending on the PV technology. The model is accurate but needs many input parameters, which change according to the characteristics of the panel. Their model was more precise with less irradiance fluctuations and under clear sky conditions.

The main objective of this paper is to model the thermal behavior of a PV panel in 1D using the finite volume method. We have described in detail the adopted numerical scheme, also discussing the model equations and the solution system. The developed model was validated, by the experimentally provided results by Hasan et al [19]. We then predicted the temperature evolution of the PV module under real climate conditions, and by comparing the results of the developed model with other models in the literature, and the experimental data.

\section{Methods and materials}

Corresponding author: ibtissamlamaamar@gmail.com 


\subsection{Thermal model and numerical approach}

The physical model studied is a PV module composed of five layers, subjected to solar irradiation, and on these two front and back sides we take account of the convection and radiation losses (See Fig. 1). The energy equations governing the thermal behaviour of the elements constituting the studied system are, in detail, exposed, as well as the assumptions retained for this problem. The numerical resolution of the heat equation governing the thermal behaviour of the system is done by the finite volume approach (FV); it would be done in a mono-dimensional way. The method has been described by the FORTRAN language.

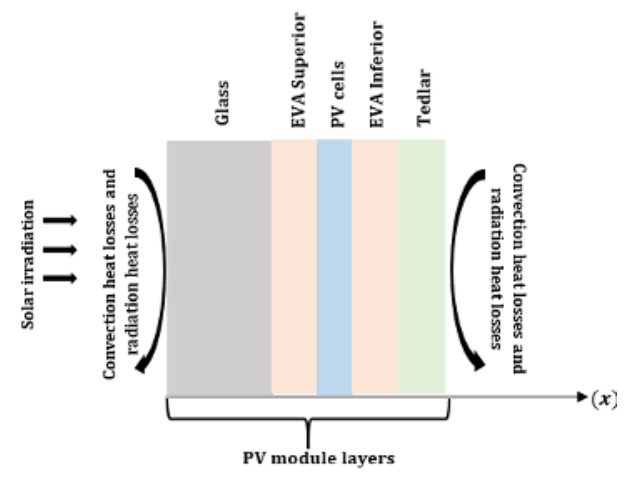

Fig. 1. Physical model of the PV module.

Several assumptions were considered about the PV module design structure, atmospheric conditions and other factors:

The contact between the layers is assumed perfect.

All material properties of the PV module layers are identical in all directions and independent of temperature.

The radiation falling on the front surface of the module is equally distributed.

La transmittance-absorption of PV module layers is independent of the wavelength of the incident irradiance.

No dust or other agents are deposited on the surface of the module that affect the absorption of the module.

\subsubsection{Heat equation and boundary conditions}

The heat equation is a partial differential equation, which describes the evolution of heat in each position (x) as a function of time ( $\mathrm{t}$ ). The 1D unsteady heat equation for a solid domain in terms of temperature is given by:

$\rho C_{p}\left(\frac{\partial T}{\partial t}\right)=k \cdot \frac{\partial}{\partial x}\left(\frac{\partial T}{\partial x}\right)+S_{i}$

$\rho, C_{p}$, and $k$ are the density, specific heat and thermal conductivity respectively.

$S_{i}$ is the internal unit volume heat output for each layer of the model, it can be obtained by:
$S_{i}=\frac{\left(1-\eta_{c}\right) \cdot G(t) \cdot \alpha_{i} \cdot \tau_{j} \cdot A_{i}}{V_{i}}$

" $\mathrm{i}$ " is the index of the active layer and " $\mathrm{j}$ " is the index of the layer above the layer " $i$ ". We supposed that $S_{i}$ cancels for the lower EVA layer and the Tedlar layer. $G(t), \alpha_{i}$, $\tau_{j}, . A_{i}$ and $V_{i}$ are respectively the solar radiation, the absorptivity, transmissivity, area and the volume of the active layer of PV module.

To solve Eq. 1, we also need some boundary conditions. On both, front and back, sides of the PV module we have losses by convection and radiation that we can express as follows:

For $\mathrm{x}=0$

$-k_{f} \frac{\partial T}{\partial x}=h_{c, f}\left(T_{a m b}-T_{f}\right)+h_{r, f}\left(T_{s k y}-T_{f}\right)$

For $\mathrm{x}=\mathrm{L}$

$-k_{b} \frac{\partial T}{\partial x}=h_{c, b}\left(T_{a m b}-T_{b}\right)+h_{r, b}\left(T_{g r}-T_{b}\right)$

Where $h_{c, f}, h_{r, f}, T_{f}$, and $T_{a m b}$ are the convective heat transfer coefficient, the radiative heat transfer coefficient, temperature of the front face of PV module and the ambient temperature. $h_{c, b}$, and $h_{r, b}$, and $T_{b}$ are the convective heat transfer coefficient, radiative heat transfer coefficient and the temperature of the back face of PV module respectively.

The convective heat transfer coefficient " $h_{c}$ " is expressed as:

$h_{c}=h_{c, f r}+h_{c, f r c}$

$h_{c, f r}$ is the free convective heat. The forced convective heat transfer coefficient " $h_{c, f r c}$ " due to the wind effect was predicted by the following correlation [21]:

$h_{c, f r c}=5.7+3.8 u_{i}$

Eq. 6 is valid for wind speed " $u_{i}$ ", lower than $5 \mathrm{~m} / \mathrm{s}$ [21].

We have expressed the radiative heat transfer coefficient of the front and rear surfaces as follows:

$\left\{\begin{array}{l}h_{r, f, s k y}=\frac{\sigma\left(T_{f}^{2}+T_{s k y}^{2}\right)\left(T_{f}+T_{s k y}\right)}{\frac{1-\varepsilon_{f}}{\varepsilon_{f}}+\frac{1}{F_{f-s k y}}} \\ h_{r, f, g r}=\frac{\sigma\left(T_{f}^{2}+T_{g r}^{2}\right)\left(T_{f}+T_{g r}\right)}{\frac{1-\varepsilon_{f}}{\varepsilon_{f}}+\frac{1}{F_{f-g r}}}\end{array}\right.$

$\left\{\begin{array}{l}h_{r, b, s k y}=\frac{\sigma\left(T_{b}^{2}+T_{s k y}^{2}\right)\left(T_{b}+T_{s k y}\right)}{\frac{1-\varepsilon_{b}}{\varepsilon_{b}}+\frac{1}{F_{b-s k y}}} \\ h_{r, b, g r}=\frac{\sigma\left(T_{b}^{2}+T_{g r}^{2}\right)\left(T_{b}+T_{g r}\right)}{\frac{1-\varepsilon_{b}}{\varepsilon_{b}}+\frac{1}{F_{b-g r}}}\end{array}\right.$

$h_{r, f, s k y}$ and $h_{r, b, s k y}$ are the radiative heat transfer coefficient of front and back side of the PV module 
dissipated toward the sky. $h_{r, f, g r}$ and $h_{r, b, g r}$ are the radiative heat transfer coefficient of front and back side of the PV module dissipated toward the ground. $\sigma, \varepsilon, \mathrm{F}$ are Stefan Boltzmann constant, emissivity, and the view factor.

The ground temperature " $T_{g r}$ " was assumed to be equal to the ambient temperature " $T_{a m b}$ ". The sky temperature " $T_{\text {sky }}$ " was difficult to calculate accurately, but could be calculated approximately by [21]:

$T_{s k y}=T_{a m b}-6(K)$

\subsubsection{Finite volume approach implementation}

We divided the PV module thickness domain into $\mathrm{N}$ equal nodes, equally spaced from each other by a distance of $\Delta \mathrm{x}$. The boundaries of the control volume are positioned halfway between two adjacent nodes. Thus, each node is enveloped by a control volume. A notation system is implemented as shown in Fig. 2. Any node is identified by $\mathrm{P}$ and its neighboring nodes in the $1 \mathrm{D}$ case are: node "W" for West and node "E" for East. The West of the control volume is denoted "w" and the East is denoted "e". The distances between nodes W and P and that between $\mathrm{P}$ and $\mathrm{E}$ are denoted $\delta x_{w}$ and $\delta x_{e}$ respectively which are equal to $\Delta \mathrm{x}$.

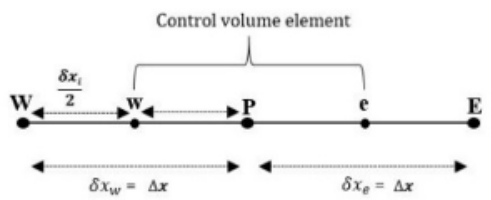

Fig. 2. Notation scheme.

Considering a uniform mesh for each layer, the integration of the heat equation (Eq. 1) over the control volume and over a time interval from $t$ to $t+\Delta t$ gives:

$\int_{t}^{t+\Delta t} \int_{v c} \rho C_{p} \cdot\left(\frac{\partial T}{\partial t}\right) d v d t=\int_{t}^{t+\Delta t} \int_{v c} \frac{\partial}{\partial x}\left(k \frac{\partial T}{\partial x}\right) d v d t+$ $\int_{t}^{t+\Delta t} \int_{v c} S_{i} d v d t$

The spatial derivative of Eq. 10 becomes:

$\int_{t}^{t+\Delta t}\left(k \cdot A \frac{\partial T}{\partial x}\right)_{e}-\int_{t}^{t+\Delta t}\left(k \cdot A \frac{\partial T}{\partial x}\right)_{w} d t=$

$\int_{t}^{t+\Delta t}\left(k_{e} \frac{T_{E}-T_{P}}{\delta x_{e}}-k_{w} \frac{T_{P}-T_{W}}{\delta x_{w}}\right) d t$

For a fully implicit scheme, the final algebraic equation is written as:

$a_{P} T_{P}=a_{E} T_{E}+a_{W} T_{W}+a_{P}^{0} T_{P}^{0}+S_{i} \Delta x$

The expression of the coefficients varies with the variation of position (node). Fig. 3 shows the control volume for nodes situated at different locations. Table 1, Table 2 and Table 3 present the corresponding expressions of the coefficients for the case of nodes located at the front / back face, internal nodes and nodes on interface respectively.
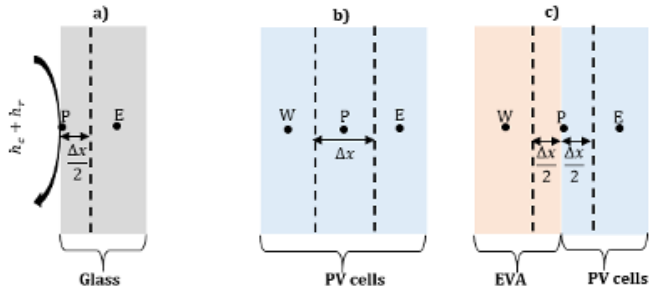

Fig. 3. The control volume for nodes located at a) at the PV module boundary, b) inside the PV module, c) at the PV module interface.

Table 1. The coefficients expression of the discretized heat equation for different nodes at PV module in different positions of the PV module.

\begin{tabular}{|c|c|c|}
\hline Coefficients & Front side & Back side \\
\hline$a_{P}$ & $\begin{array}{l}\rho C_{P} \frac{\Delta x}{2 . \Delta t}+\frac{k_{e}}{\delta x_{e}} \\
+h_{f}+h_{r, f}\end{array}$ & $\begin{array}{l}\rho C_{P} \frac{\Delta x}{\Delta t}+\frac{k_{e}}{\delta x_{e}}-h_{b} \\
-h_{r, b}\end{array}$ \\
\hline$a_{E}$ & $\frac{k_{e}}{\Delta x}$ & 0 \\
\hline$a_{W}$ & 0 & $\frac{k_{w}}{\Delta x}$ \\
\hline $\mathrm{a}_{\mathrm{P}}^{0}$ & $\rho C_{P} \frac{\Delta x}{2 . \Delta t}$ & $\rho C_{P} \frac{\Delta x}{2 . \Delta t}$ \\
\hline$P_{f}$ & $\begin{array}{l}S_{i} \frac{\Delta x}{2}+h_{f} T_{a m b} \\
+h_{r, f} T_{a m b}\end{array}$ & $\begin{array}{l}S_{i} \frac{\Delta x}{2}-h_{v} T_{a m b} \\
-h_{r, b} T_{a m b}\end{array}$ \\
\hline Coefficients & \multicolumn{2}{|c|}{ Internal points } \\
\hline$a_{P}$ & \multicolumn{2}{|c|}{$\rho C_{P} \frac{\Delta x}{\Delta t}+\frac{k_{e}}{\delta x_{e}}+\frac{k_{w}}{\delta x_{w}}$} \\
\hline$a_{E}$ & & $\frac{e}{x}$ \\
\hline$a_{W}$ & & $\frac{w}{x}$ \\
\hline $\mathrm{a}_{\mathrm{P}}^{0}$ & & $\frac{\Delta x}{\Delta t}$ \\
\hline$P_{f}$ & \multicolumn{2}{|c|}{$S_{i} \cdot \Delta x$} \\
\hline Coefficients & \multicolumn{2}{|c|}{ Interface } \\
\hline$a_{P}$ & $\left(\left(\rho C_{p}\right)_{i}+\left(\rho C_{p}\right.\right.$ & $\frac{\Delta x}{2 . \Delta t}+\frac{k_{w}}{\delta x_{w}}+\frac{k_{e}}{\delta x_{e}}$ \\
\hline$a_{E}$ & & \\
\hline$a_{W}$ & & $\frac{w}{x}$ \\
\hline $\mathrm{a}_{\mathrm{P}}^{0}$ & $\left(\left(\rho C_{p}\right)_{i}\right.$ & $\left.\left.C_{p}\right)_{i+1}\right) \frac{\Delta x}{2 \cdot \Delta t}$ \\
\hline$P_{f}$ & & $\Delta x$ \\
\hline
\end{tabular}

The numerical discretization methods (FV) used reduced the resolution of the system of differential equations in the study domain, with appropriate boundary conditions, to 
those of a system of algebraic equations, which we can transform into a tri-diagonal matrix system as follows: :

$$
[A] .[T]=[B]
$$

$$
\left[\begin{array}{cccccccc}
b_{1} & c_{1} & 0 & 0 & \ldots & \ldots & 0 & 0 \\
a_{2} & b_{2} & c_{2} & 0 & & & & 0 \\
0 & a_{3} & b_{3} & c_{3} & 0 & \vdots & \vdots & 0 \\
0 & 0 & a_{4} & b_{4} & c_{4} & 0 & & \vdots \\
\vdots & & 0 & \ddots & \ddots & \ddots & 0 & 0 \\
\vdots & & & 0 & \ddots & \ddots & c_{n 2} & 0 \\
0 & & & \vdots & 0 & a_{n 1} & b_{n 1} & c_{n 1} \\
0 & 0 & 0 & \ldots & 0 & 0 & a_{n} & b_{n}
\end{array}\right]\left[\begin{array}{c}
T_{1} \\
T_{2} \\
T_{3} \\
\vdots \\
\vdots \\
T_{n 1} \\
T_{n}
\end{array}\right]=\left[\begin{array}{c}
d_{1} \\
d_{2} \\
d_{3} \\
\vdots \\
\vdots \\
\\
d_{n 1} \\
d_{n}
\end{array}\right]
$$

We apply the Thomas algorithm iteratively adapted to 1D problems.

\subsection{Experiment system and procedure}

An experimental system has been set up and located on the roof of the physics department of the Faculty of Science and Technology of Er-Rachidia (31' 55' 55 N, -4' $25 ' 28 \mathrm{E}$ ). A polycrystalline photovoltaic (PV) module of $300 \mathrm{~mm} \times 350 \mathrm{~mm}$ is used.

The module temperature was measured using thermocouples (T-type, copper-constantan) which placed at the front of the PV module on July 25, 2020 in Errachidia from 08:00h to 20:00h and Fig. 7 shows the external ambient temperature and the global solar irradiance at Errachidia-Morocco emitted on the PV module on July 25, 2020. The average value of the convective heat transfer coefficient $\mathrm{h}$ is $11.4 \mathrm{~W} \mathrm{~m}^{-2} \mathrm{~K}^{-1}$.

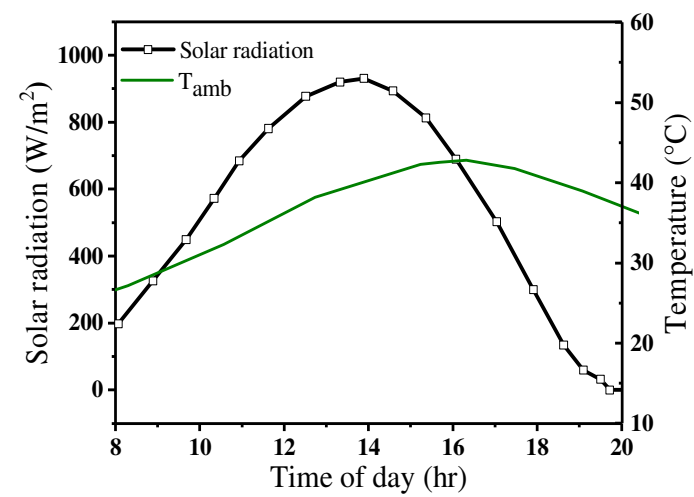

Fig. 4. Solar radiation and ambient temperature variation for 25 July 2020.

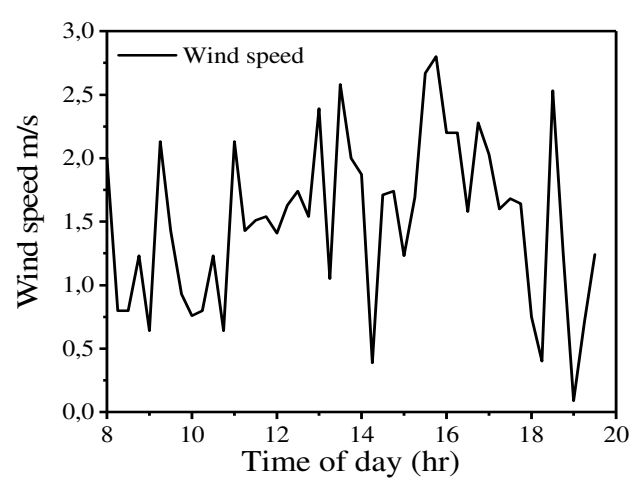

Fig. 5. Wind speed variation for 25 July 2020.

\subsection{Experiment system and procedure}

To evaluate the effectiveness of the thermal model modelled by the FV 1-D approach, it was subjected to a validation test. The computer used for the simulations, had the following characteristics, $3 \mathrm{GHz}$ Xeon CPU and 8 GB of RAM. For all simulations, $\Delta \mathrm{x}$ is given as $0.01 \mathrm{~mm}$ and $\Delta \mathrm{t}$ is given as 60 secs. The present model was validated for a PV module by a previous experimental study by Hasan et al. [19], The temperature variation of the PV module is calculated from the model and compared with the study of Hasan et al. [19] as shown in Fig. 6. The results of the computer simulations were consistent with the results obtained by Hasan et al [19].
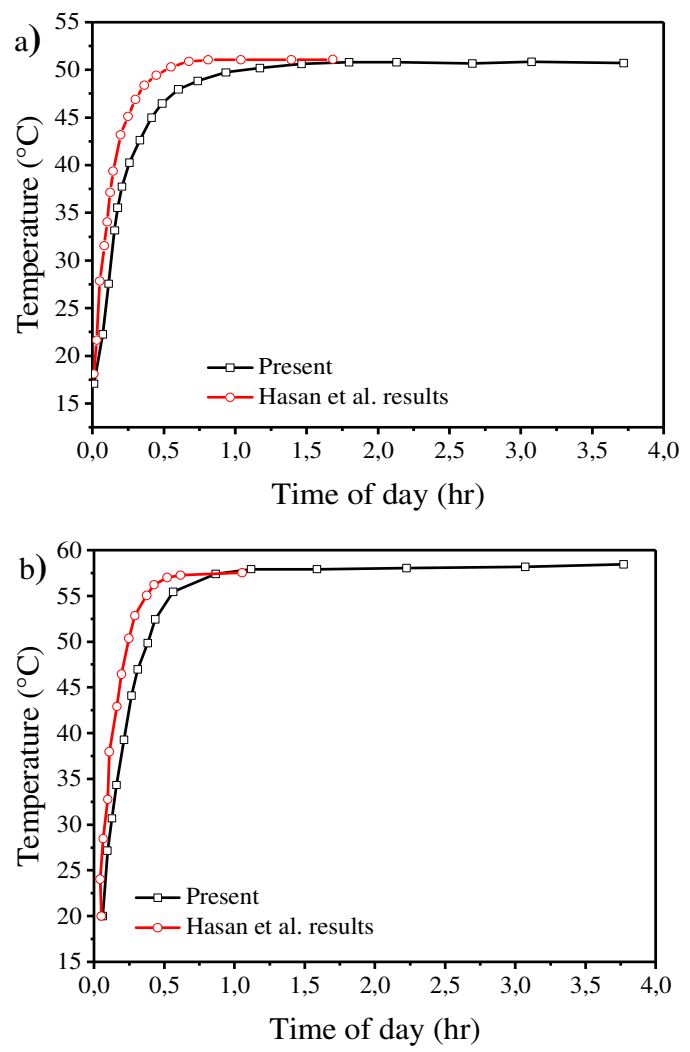

Fig. 6. Wind speed variation model validation with Hasan et al [19] a) at $700 \mathrm{~W} / \mathrm{m}^{2}$; b) at $1000 \mathrm{~W} / \mathrm{m}^{2}$ and ambient temperature of $20 \pm 1{ }^{\circ} \mathrm{C}$ 


\section{Results and discussion}

The temperature of the PV module was determined, and the experimentally obtained results were compared to those obtained using the developed model. The PV module is subjected to the environmental conditions of 25 July 2020.

We verified the accuracy of our model by comparing it to other approaches in the literature. We tested four different models for predicting temperature in the PV cell and, which calculate the cell temperature as a function of incoming solar irradiance, meteorological parameters of the region and parameters related to the PV module. The first model tested is the most currently used, standard approach, which does not include the effect of wind cooling in the calculation of the PV cell temperature. It is a function of the ambient temperature $T_{a m b}$ and the incident solar radiation $(\mathrm{G})$, the incident NOCT radiation $\left(G_{N O C T}\right)$ which is $800 \mathrm{~W} / \mathrm{m}^{2}$, the nominal NOCT temperature of the PV panel $\left(T_{N O C T}\right)$ and the ambient temperature at NOCT $\left(T_{a m b, N O C T}\right)$ which is $20^{\circ} \mathrm{C}$, its expression is expressed by:

$T_{P V, \text { cell }}=T_{a m b}+\frac{G}{G_{N O C T}}\left(T_{N O C T}-T_{a m b, N O C T}\right)$

The Kurtz model takes into account the wind speed to predict the temperature of the model, but includes no parameters related to the PV module to distinguish between module technologies; its expression is the following [11]:

$T_{P V, \text { cell }}=T_{a m b}+G \cdot e^{-3.473-0.0594 v_{w}}$

$T_{a m b}$ is the ambient temperature, $G$ the incident solar irradiance and $v_{w}$ is the local wind speed close to the PV module.

Koehl et al. [10] used a simple empirical model, which estimates the cell temperature $T_{P V, \text { cell }}$ as a function of the irradiance $\mathrm{G}$, the ambient temperature $T_{a m b}$ and the local wind speed near the modules $v_{w}$ and the constants $\mathrm{U}_{0}$ which is equal to 30.02 and $U_{1}$ which is equal to 6.28 for the polycrystalline technology

$T_{P V, \text { cell }}=T_{a m b}+\frac{G}{U_{0}+U_{1} v_{w}}$

Skoplaki et al [12] improved the Standard approach by adding wind speed and module-specific properties such as efficiency, maximum temperature coefficient of power and other optical properties related to the PV module to the Standard approach expression:

$$
\begin{aligned}
& T_{P V, \text { cell }}=T_{a}+\frac{G}{G_{N O C T}} *\left(T_{N O C T}-T_{a, N O C T}\right) * \frac{h_{w, N O C T}}{h_{w}(v)} * \\
& {\left[1-\frac{\eta_{S T C}}{\tau \alpha}\left(1-\beta_{S T C} T_{S T C}\right)\right]}
\end{aligned}
$$

To evaluate the performance of the developed model compared to the others models, some performance indicators can be used. We calculated the Bias (Eq. 19), which is a reliability standard that describes the difference between the observation and the measurement. The Root
Mean Square Error (RMSE) criteria (Eq. 20), which describes the characterization of the difference between observation and measurement; it is a precision criteria. Nash-Sutcliffe (NS) (Eq. 21) standard, which estimates the ability of the model to reproduce the observed behaviour.

$$
\begin{aligned}
& \text { Bias }=\frac{1}{n} \sum_{i=1}^{n}\left(X_{o b s, i}-X_{\text {sim }, i}\right) \\
& R M S E=\sqrt{\frac{1}{n} \sum_{i=1}^{n}\left(X_{o b s, i}-X_{\text {sim }, i}\right)^{2}} \\
& N S=1-\frac{\sum_{i=1}^{n}\left(X_{o b s, i}-X_{\text {sim }, i}\right)^{2}}{\sum_{i=1}^{n}\left(X_{o b s, i}-X_{\text {sim }, i}\right)^{2}}
\end{aligned}
$$

Table 4. Performances of appliqued models to predict the PV cell temperature.

\begin{tabular}{|l|l|l|l|}
\hline & Bais & RMSE & NS \\
\hline Model developed & 0.27 & 0.932 & 0.99 \\
\hline Standard approach & 1.95 & 4.30 & 0.90 \\
\hline Kurtz's model & 0.83 & 1.52 & 0.97 \\
\hline Koehl's model & -0.81 & 1.53 & 0.97 \\
\hline Skoplaki's model & -0.54 & 1.39 & 0.98 \\
\hline
\end{tabular}

Fig. 7 and Fig. 8 show the measured and predicted temperature, using the model developed and, the temperature predicting models in the literature respectively. Fig. 8-a) and Table 5 show that the Standard approach is less accurate for calculating the PV cell temperature, with the highest Bias and RMSE of 1.95 and 4.30 respectively. The other three models have almost the same accuracy.

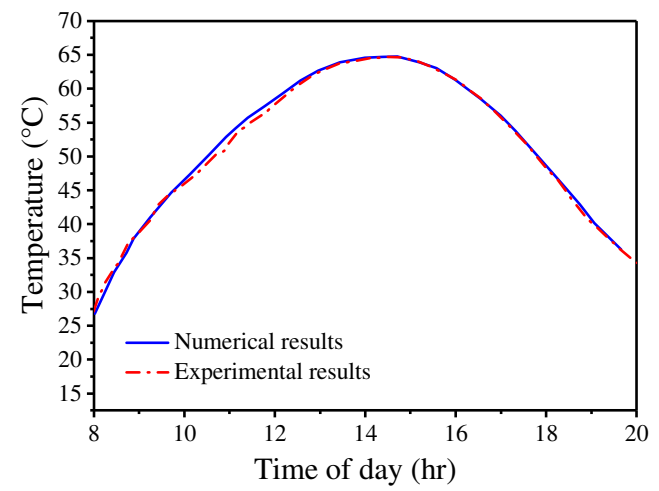

Fig. 7. PV module temperature evolution for the experiment results and results of prediction models. 

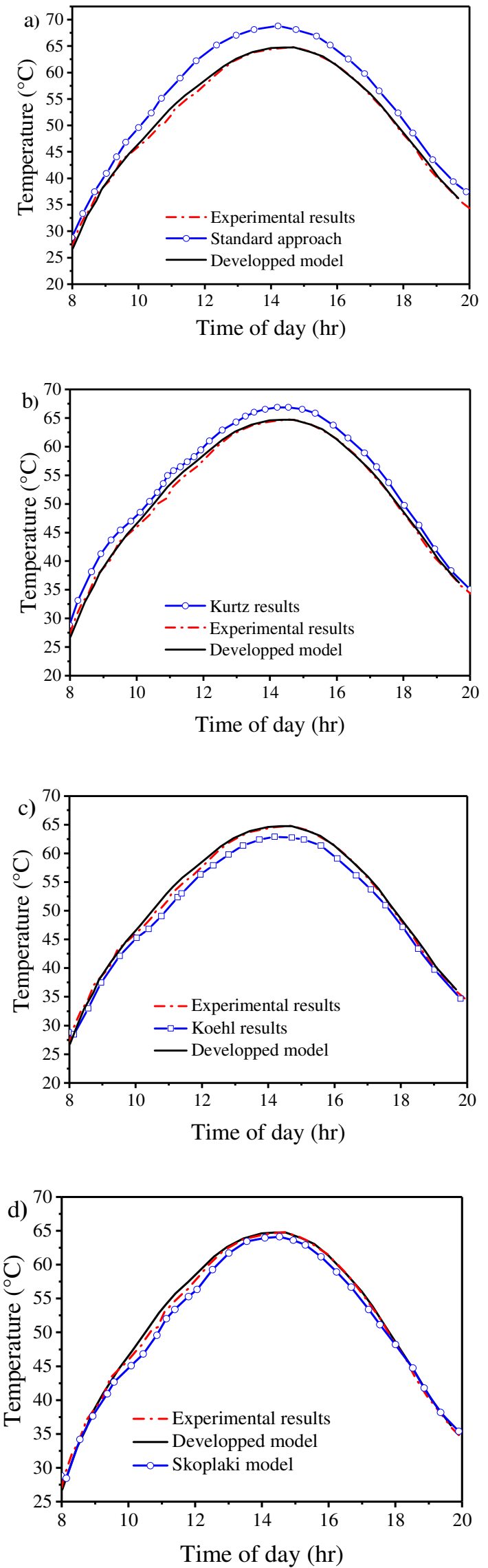

Fig. 8. PV module temperature evolution for the experiment results and results of prediction models.
- While the other two approaches (Fig. 8 (b)-(c)) have about the same performance indices (Bias, RMSE and NS) (see Table. 4). The only difference between them is that, only the Kurtz approach shows an over-prediction of the cell temperature, while the Koehl model presents an under-prediction of this temperature.

As shown in Fig. 8-d) The Skoplaki model is more accurate than the Kurtz and Koehl model and the standard approach with a low RMSE of $1.39^{\circ} \mathrm{C}$. We recall that the Skoplaki model is a variant of the Standard approach.

Finally, the developed model, with an RMSE of $0.932^{\circ} \mathrm{C}$ and a NS of 0.99 remains the most accurate and the best when compared with all tested analytical temperature prediction models, and the predicted temperature are very closer to the measured temperature. The developed model includes all the methodological parameters that can affect the thermal behaviour of the PV module, and the parameters related to the materials constituting the PV module too. We have taken into consideration the convection and radiation losses on both sides of the PV module. All these parameters can improve the model operation and make it more accurate.

\section{Conclusion}

A precise numerical thermal model based for PV module has been developed and described in detail, and the heat transfer is considered one-dimensional.

The PV module exchanges heat the external environment; this exchange is influenced by several variables such as the weather conditions, the heat transfer coefficients (radiative and convective), the geometry and the thermophysical properties of all materials composing the system. Our model has been developed in order to respect most of these real conditions. To check the accuracy of our model, a comparison was made between the predicted numerical results obtained by the developed model, the experimentally obtained data and other approaches in the literature, which predict the cell temperature. We have based on different statistics error parameters, to judge the accuracy criteria of each model, which give a general idea about the difference between the measured and predicted temperatures. The result shows that the developed model is the best and most accurate, with an RMSE of $0.932^{\circ} \mathrm{C}$, a NS of 0.99 and a bias of $0.27{ }^{\circ} \mathrm{C}$. Finally, we point out that this result can be improved by improving the parameters of the grid (FV) and the time step. The accuracy found for other models can change with the climatic conditions and with the technology of the model, contrary to the developed model, which can adapt with any condition and PV technology.

\section{References}

[1] P. Atkin and M. M. Farid, "Improving the efficiency of photovoltaic cells using PCM infused graphite and aluminium fins," Sol. Energy, vol. 114, pp. 217-228, 2015

[2] K. Kant, A. Shukla, A. Sharma, and P. Henry, "Thermal response of poly-crystalline silicon photovoltaic panels: Numerical simulation and 
experimental study," Sol. Energy, vol. 134, pp. 147-155, (2016)

[3] J. K. Tonui and Y. Tripanagnostopoulos, "Aircooled PV/T solar collectors with low cost performance improvements," Sol. Energy, vol. 81, pp. 498-511, (2007)

[4] H. Pierrick, M. Christophe, G. Leon, and D. Patrick, "Dynamic numerical model of a high efficiency PV-T collector integrated into a domestic hot water system," Sol. Energy, vol. 111, pp. 68-81, (2015)

[5] J. H. Eckstein, "Detailed Modelling of Phtovoltaic System Components," M.S. Thesis. Madison: University of Wisconsin; p. 32-40, (1990)

[6] R. Salehi, A. Jahanbakhshi, M. Reza Golzarian, and M. Khojastehpour, "Evaluation of solar panel cooling systems using anodized heat sink equipped with thermoelectric module through the parameters of temperature, power and efficiency," Energy Convers. Manag. X, vol. 11, p. 100102, (2021)

[7] G. Notton, C. Cristofari, M. Mattei, and P. Poggi, "Modelling of a double-glass photovoltaic module using finite differences," Appl. Therm. Eng., vol. 25, pp. 2854-2877, (2005)

[8] J. C. Sánchez Barroso, N. Barth, J. P. M. Correia, S. Ahzi, and M. A. Khaleel, "A computational analysis of coupled thermal and electrical behavior of PV panels," Sol. Energy Mater. Sol. Cells, vol. 148, pp. 73-86, (2016)

[9] M. Mattei, G. Notton, C. Cristofari, M. Muselli, and P. Poggi, "Calculation of the polycrystalline PV module temperature using a simple method of energy balance," Renew. Energy, vol. 31, pp. 553-567, (2006)

[10] M. Koehl, M. Heck, S. Wiesmeier, and J. Wirth, "Modeling of the nominal operating cell temperature based on outdoor weathering," Sol. Energy Mater. Sol. Cells, vol. 95, pp. 1638-1646, (2011)

[11] S. Kurtz et al., "Evaluation of High-Temperature Exposure of Photovoltaic Modules: Preprint," Nrel, pp. 2399-2404, (2009)

[12] E. Skoplaki, A. G. Boudouvis, and J. A. Palyvos, "A simple correlation for the operating temperature of photovoltaic modules of arbitrary mounting," Sol. Energy Mater. Sol. Cells, vol. 92, pp. 1393-1402, (2008)

[13] A. D. Jones and C. P. Underwood, "A thermal model for photovoltaic systems," Fuel Energy Abstr., vol. 43, p. 199, (2002)

[14] F. Sarhaddi, S. Farahat, H. Ajam, A. Behzadmehr, and M. Mahdavi Adeli, "An improved thermal and electrical model for a solar photovoltaic thermal (PV/T) air collector," Appl. Energy, vol. 87, pp. 2328-2339, (2010)

[15] Y. Lee and A. A. O. Tay, "Finite element thermal analysis of a solar photovoltaic module," Energy Procedia, vol. 15, pp. 413-420, (2012)

[16] S. Armstrong and W. G. Hurley, "A thermal model for photovoltaic panels under varying atmospheric conditions," Appl. Therm. Eng., vol. 30, pp. 1488-1495,( 2010)

[17] G. M. Tina and S. Scrofani, "Electrical and thermal model for PV module temperature evaluation," Proc. Mediterr. Electrotech. Conf. MELECON, pp. 585-590, (2008)

[18] D. L. King, W. E. Boyson, and J. A. Kratochvil, "Photovoltaic array performance model," Sandia Rep. No. 2004-3535, vol. 8, pp. 1-19, (2004)

[19] A. Hasan, S. J. McCormack, M. J. Huang, and B. Norton, "Evaluation of phase change materials for thermal regulation enhancement of building integrated photovoltaics," Sol. Energy, vol. 84, pp. 1601-1612,(2010)

[20] M. Emam and M. Ahmed, "Cooling concentrator photovoltaic systems using various configurations of phase-change material heat sinks," Energy Convers. Manag., vol. 158, no. January, pp. 298-314, (2018)

[21] J. cheng Zhou, Z. Zhang, H. jian Liu, and Q. Yi, "Temperature distribution and back sheet role of polycrystalline silicon photovoltaic modules," Appl. Therm. Eng., vol. 111, pp. 1296-1303, (2017) 